\title{
Analisis Kinerja Manajemen PT. Sariguna Primatirta Tbk. Menggunakan Metode Balanced Scorecard Periode 2018-2020
}

\author{
Mohammad Khoiruzi Afiq \\ Universitas Islam Negeri Sunan Ampel \\ khoiruziafiq@gmail.com \\ Helmina Ardyanfitri \\ Universitas Islam Negeri Sunan Ampel \\ helmina.ardyanfitri@uinsby.ac.id
}

\begin{abstract}
The high demand for quality drinking water in Indonesia, at least Indonesia needs 570.40 million liters every day. PT Sariguna Primatirta Tbk is a drinking water producer with the first producer in Indonesia to receive a food safety management ISO 22000: 2005 certificate and has a Top Brand Index 2021 achievement of $39.7 \%$ with the first rank in the Oxygenated Bottled Drinking Water category. Management performance appraisal is important not only for internal, but also for the government, investors and the general public. This assessment can be used as a tool used to assess the level of efficiency and effectiveness of management in implementing strategies and preventing company losses. This study aims to determine the management performance of PT Sariguna Primatirta Tbk for the 2018-2020 period using the Balanced Scorecard method. The method used in this research is descriptive quantitative research. The object of this research is the Financial Statements of PT Sariguna Primatrita Tbk for 2018-2020. The results of this study indicate that the performance of PT Sariguna Primatirta Tbk in 2018 to 2019 is categorized as good by getting a total score of 16. However, in 2019 to 2020 there was a decline in performance due to non-optimal use of all assets to generate company profits but still got a total score of 10.
\end{abstract}

Keywords: Performance Management, Balanced Scorecard.

\section{PENDAHULUAN}

Air merupakan unsur yang penting dalam kehidupan manusia sebab tubuh manusia tidak dapat memproduksi air sendiri sehingga diperlukan asupan air minum yang cukup (Ernovitania \& Sumarmi, 2017). Setidaknya kebutuhan air minum yang diperlukan manusia berdasarkan pedoman umum gizi seimbang (PUGS) adalah sekitar 8 gelas air minum berukuran $230 \mathrm{ml}$ atau setara dengan 2 liter setiap harinya (Briawan, Sedayu, \& Ekayanti, 2011). Menurut Badan Pusat Statistika jumlah penduduk Indonesia pada tahun 2020 mencapai 270,20 juta jiwa (Badan Pusat Statistik, 2021). Jika setiap orang membutuhkan setidaknya 2 liter setiap harinya, maka Indonesia membutuhkan pasokan air minum sebanyak 570,40 juta liter setiap hari. Fenomena ini menunjukkan bahwa Indonesia memiliki permintaan yang tinggi terhadap air minum yang berkualitas sehingga kondisi tersebut menunjukkan potensi pasar yang besar untuk perusahaan yang bergerak di bidang konsumer khususnya produksi air minum. 
PT Sariguna Primatirta merupakan perusahaan yang didirikan sejak 1988 yang bergerak di sektor konsumer sebagai produsen Air Minum Dalam Kemasan (AMDK) dan merupakan produsen pertama di Indonesia yang mendapatkan sertifikat food safety management ISO 22000: 2005 (PT Sariguna Primatirta Tbk, 2020). Selain itu, PT Sariguna Primatrita mendapatkan prestasi Top Brand Index 2021 sebesar 39,7\% dengan peringkat pertama kategori Air Minum Dalam Kemasan Beroksigen (Top Brand Index, 2021). Melihat besarnya potensi pasar Indonesia terhadap kebutuhan AMDK dan potensi kualitas produk Cleo dari PT Sariguna Primatirta, maka penilaian kinerja perusahaan sangatlah penting dilakukan untuk mengetahui bagaimana pencapaian tingkat efisiensi dan efektivitas dari aktivitas operasional manajemen perusahaan dalam mencapai tujuannya (Putra, 2012).

Penilaian kinerja perusahaan tidaklah cukup jika hanya mengandalkan pada prespektif keuangan saja, sebab prespektif keuangan belum cukup mewakilkan untuk menyimpulkan baik atau tidaknya kinerja perusahaan (Ikasari, Silalahi, \& Effendi, 2018). Melihat urgensi penilaian kinerja perusahaan, maka penilaian harus dilakukan secara komprehensif dari berbagai aspek sehingga hasil analisa atas penilaian kinerja tersebut akurat sehingga memudahkan perusahaan dalam mengambil kebijakan yang tepat dalam mengambil keputusan (Farhan, Kurniawan, \& Fitria, 2016). Balanced Scorecard merupakan salah satu alternatif metode terintegrasi yang mencakup 4 prespektif (keuangan, pelanggan, proses bisnis internal, serta pembelajaran dan inovasi) dalam proses penilaiannya yang dapat digunakan oleh seorang analis dalam melakukan penilaian suatu kinerja perusahaan sehingga hasil yang didapatkan lebih akurat untuk digunakan sebagai acuan dalam pengambilan keputusan (Jumingan, 2017).

\section{KAJIAN PUSTAKA \\ Penilaian Kinerja}

Kinerja perusahaan merupakan suatu prestasi atau pencapaian perusahaan dalam memaksimalkan pemanfaatan sumber daya yang dimiliki untuk mencapai target visi dan misi perusahaan dalam suatu periode tertentu (Fahrudin, 2020). Sedangkan, Hidayat mendifiniskan kinerja merupakan kemampuan suatu program yang dirancang dengan formulasi strategi yang matang melalui kebijakan, visi dan misi perusahaan dalam rangka mewujudkan sasaran dan tujuan perusahaan (Fahrudin, 2020).

Penilaian kinerja merupakan suatu tindakan yang digunakan untuk menilai tingkat efektivitas seluruh rantai aktivitas perusahaan dalam mencapai tujuannya yang didasarkan pada acuan standar yang telah ditetapkan (Rahmawati, Dzulkirom AR, \& Husaini, 2013). Menurut Mulyadi manfaat adanya penilaian kinerja yaitu perusahaan mampu menilai seberapa efektif dan efisien setiap karyawan dalam menjalankan operasional perusahan, membantu dalam pengambilan keputusan, 
menilai seberapa efisien dan efektif implementasi manajemen strategis perusahaan dan bahan evaluasi mengenai kebutuhan keterampilan para karyawan serta sebagai dasar dan acuan dalam memberikan apresiasi kepada karyawan yang memiliki kinerja optimal (Wutun, 2020).

\section{Balanced Scorecard}

Balanced Scorecard merupakan sebuah metode penilaian kinerja suatu perusahaan yang dikembangkan oleh Drs. Robert Kalpan dan David P Norton pada awal tahun 1990 (Aramana, 2020). Metode ini merupakan suatu alat yang dapat digunakan oleh para manajer perusahaan sebagai indikator dan ukuran dalam menilai kinerja perusahaan melalui 4 pendekatan yang didasarkan pada aspek keuangan maupun non keuangan, diantaranya yaitu prespektif keuangan, prespektif pelanggan, prespektif proses bisnis internal serta prespektif pembelajaran dan pertumbuhan (Aini \& Sutjahyani, 2020).

Metode Balanced Scorecard merupakan alat penilai kinerja yang terintegrasi yang dapat menerjemahkan visi, misi dan strategi perusahaan yang terbagi dalam 4 macam prespektif (Wutun, 2020):

\section{Prespektif Keuangan}

Dalam metode Balanced Scorecard, penilaian terhadap aspek keuangan ditujukan untuk melihat bagaimana tingkat efektivitas dan efisiensi perusahaan dalam mengimplementasikan strategi untuk meningkatkan tujuan keuangan atau laba perusahaan (Aramana, 2020). Hal ini dapat diukur melalui beberapa indikator, diantaranya yaitu:

a. Return On Asset (ROA), yang menggambarkan efektivitas kinerja manajemen atau tingkat kemampuan perusahaan dalam menghasilkan keuntungan melalui pemanfaatan seluruh aset yang dimilikinya (Kasmir, 2019). Semakin besar rasio ini maka akan semakin baik.

Rumus:

Return On Asset $=\frac{\text { Laba Bersih Setelah Pajak }}{\text { Total Aset }}$

b. Return On Equity (ROE), yang menggambarkan tingkat efisiensi kinerja perusahaan dalam menghasilkan keuntungan dengan menggunakan modal yang dimilikinya (Kasmir, 2019). Semakin besar rasio ini maka akan semakin baik.

Rumus:

Return On Equity $=\frac{\text { Laba Bersih Setelah Pajak }}{\text { Total Equity }}$

c. Operating Profit Margin (OPM), yang menggambarkan seberapa besar kinerja perusahaan dalam menghasilkan keuntungan dari aktivitas 
operasionalnya (Riana, 2017). Semakin besar rasio ini maka akan semakin baik.

Rumus:

Operating Margin $=\frac{\text { Pendapatan Operasional }}{\text { Penjualan Bersih }}$

d. Total Assets Turn Over (TATO), yang menggambarkan bagaimana tingkat produktivitas aktiva perusahaan atau seberapa besar kinerja seluruh aset perusahaan dalam menghasilkan penjualan (Riana, 2017). Semakin besar rasio ini maka akan semakin baik.

Rumus:

Total Assets Turn Over $=\frac{\text { Penjualan }}{\text { Total Aktiva }}$

\section{Prespektif Pelanggan}

Dalam metode balanced scorecard, Prespektif pelanggan merupakan aspek penting yang harus dinilai. Penilaian ini dilakukan untuk meninjau kinerja perusahaan dalam memberikan pelayanan maupun produk kepada konsumen sehingga dapat terpuaskan dalam pengalaman pemakian produk maupun jasa yang ditawarkan oleh perusahaan (Aramana, 2020). Penilaian ini dapat diukur melalui seberapa besar tingkat profitabilitas yang dihasilkan melalui pelanggan.

\section{Prespektif Proses Bisnis Internal}

Dalam metode balanced scorecard, penilaian kinerja perusahaan juga harus memerhatikan operasional perusahaan yang mencakup perencanaan strategi, implementasi strategi hingga evaluasi strategi. Sebab, tanpa aktivitas operasional yang baik, maka akan berdampak pada ketidakpuasan konsumen akan pelayanan yang diberikan sehingga perusahaan dapat mengalami kerugian dan sebaliknya jika aktivitas operasional optimal, maka pelayanan yang diberikan juga akan maksimal sehingga kepuasan pelanggan akan meningkat yang diiringi dengan meningkatnya loyalitas dan keuntungan perusahaan (Aramana, 2020).

4. Prespektif Pertumbuhan dan pengembangan

Dalam metode balanced scorecard, penilaian terhadap prespektif pertumbuhan dan pengembangan ditujukan untuk menilai bagaimana produktivitas dan kemajuan perusahaan dalam memaksimalkan pemanfaatan sumber daya yang dimiliki guna meningkatkan laba dan nilai serta prospek jangka panjang perusahaan (Riana, 2017). Penilaian ini dapat diukur melalui tingkat produktivitas karyawan.

\section{Penentuan Skor Range Kinerja Balanced Scorecard}


Proses penentuan skor range kinerja menggunakan balanced scorecard dapat dilakukan dengan cara membandingkan pencapaian kinerja pada suatu periode dengan pencapaian kinerja periode sebelumnya sehingga dapat diklasifikasikan sebagai berikut (Riana, 2017):

$$
\text { Range kinerja }=\frac{\text { Pencapaian Kinerja Periode }(n)-\text { Pencapaian Kinerja Periode }(n-1)}{\text { Pencapaian Kinerja Periode }(n-1)}
$$

Tabel 1 Penentuan Score Balanced Scorecard Berdasarkan Range Hasil Penilaian Kinerja

\begin{tabular}{ccc}
\hline Range Kinerja & Rate & Score \\
\hline$<\mathbf{0 \%}$ & $\mathrm{D}$ & 1 \\
$\mathbf{0 - 5 0 \%}$ & $\mathrm{C}$ & 2 \\
$\mathbf{5 1 - \mathbf { 1 0 0 \% }}$ & $\mathrm{B}$ & 3 \\
$>\mathbf{1 0 0 \%}$ & $\mathrm{A}$ & 4 \\
\hline
\end{tabular}

Sumber : (Riana, 2017)

\section{METODE PENELITIAN}

Jenis metode yang digunakan dalam penelitian ini adalah penelitian kuantitatif deskriptif. Penelitian kuantitatif deskriptif merupakan penelitian deskritif yang menggunakan pendekatan kuantitatif karena penelitian ini berkaitan erat dengan data berupa angka yang dapat dideskripsikan dan memiliki makna (Jayusman \& Shavab, 2020).

Jenis data yang digunakan dalam penelitian ini adalah data sekunder. Objek penelitian ini adalah laporan keuangan PT Sariguna Primatirta periode 2018-2020. Teknik pengumpulan data yang digunakan dalam penelitian ini adalah teknik dokumentasi dimana pengumpulan data dilakukan melalui dokumen seperti buku, jurnal, laporan perusahaan dan lain-lain (Creswell, 2017). Sehingga data yang digunakan dalam penelitian ini yaitu laporan keuangan PT Sariguna Primatirta periode 2018-2020 dan data studi kepustakaan berupa buku dan jurnal yang sesuai dengan data yang dibutuhkan dalam penelitian.

Teknik analisis data yang digunakan dalam penelitian ini adalah analisis kinerja manajemen PT Sariguna Primatirta menggunakan metode balanced scorecard yang didasarkan pada 4 prespektif yaitu prespektif keuangan menggunakan indikator ROA, ROE, OPM, dan TATO, prespektif pelanggan 
Mohammad Khoiruzi Afiq, Helmina Ardyanfitri

Analisis Kinerja Manajemen PT Sariguna Primatirta TBK Menggunakan

menggunakan indikator perbandingan jumlah penerimaan kas dari pelanggan dengan periode sebelumnya, prespektif proses bisnis internal menggunakan indikator perbandingan operating profit dengan periode sebelumnya, serta prespektif pembelajaran dan pertumbuhan menggunakan indikator perbandingan kinerja laba bersih yang diterima per karyawan (Riana, 2017).

\section{HASIL DAN PEMBAHASAN}

Analisis kinerja manajemen PT Sariguna Primatirta 2018-2020 menggunakan metode balanced scorecard dapat diukur melalui hasil laporan keuangan dengan menggunakan indikator 4 prespektif yaitu keuangan, pelanggan, proses bisnis internal, pertumbuhan dan pengembangan.

Tabel 2 Total Balanced Scorecard PT Sariguna Primatrita periode 2019-2018 dan 2020-2019

\begin{tabular}{|c|c|c|}
\hline Indikator & $\begin{array}{c}\text { Score } \\
\mathbf{2 0 1 9 - 2 0 1 8}\end{array}$ & $\begin{array}{c}\text { Score } \\
\mathbf{2 0 2 0 - 2 0 1 9}\end{array}$ \\
\hline Prespektif Keuangan & 8 & 5 \\
\hline Prespektif Customer & 2 & 1 \\
\hline Prespektif Proses Bisnis Internal & 3 & 2 \\
\hline Prepektif Pertumbuhan dan Pengembangan & 3 & 2 \\
\hline Total Score PT Sariguna Primatirta TBK & 16 & 10 \\
\hline
\end{tabular}

Sumber: Data diolah

1. Prespektif Keuangan diukur melalui indikator ROA, ROE, OPM dan Total Assets Turn Over.

Tabel 3 Hasil Penilaian Prespektif Keuangan PT Sariguna Primatirta 2018-2020

\begin{tabular}{|c|c|c|c|c|c|c|c|c|}
\hline \multirow{2}{*}{ Indikator } & \multirow{2}{*}{2018} & \multirow{2}{*}{2019} & \multirow{2}{*}{2020} & \multirow{2}{*}{ Average } & \multicolumn{4}{|c|}{ Balanced Scorecard } \\
\hline & & & & & 2019-2018 & Score & 2020-2019 & Score \\
\hline Return On Asset & $7,59 \%$ & $10,50 \%$ & $10,30 \%$ & $9,46 \%$ & $38 \%$ & $\mathrm{C}$ & $-2 \%$ & $\mathrm{D}$ \\
\hline Return On Equity & $9,96 \%$ & $17,06 \%$ & $14,84 \%$ & $13,95 \%$ & $71 \%$ & $\mathrm{~B}$ & $-13 \%$ & $\mathrm{D}$ \\
\hline $\begin{array}{c}\begin{array}{c}\text { Operating Profit } \\
\text { Margin }\end{array} \\
\end{array}$ & $13,00 \%$ & $18,97 \%$ & $21,90 \%$ & $17,95 \%$ & $46 \%$ & $\mathrm{C}$ & $15 \%$ & $\mathrm{C}$ \\
\hline $\begin{array}{c}\text { Total Assets Turn } \\
\text { Over } \\
\end{array}$ & $99,66 \%$ & $87,13 \%$ & $74,19 \%$ & $86,99 \%$ & $-13 \%$ & D & $-15 \%$ & $\mathrm{D}$ \\
\hline \multicolumn{5}{|c|}{ Total Scorecard } & & 8 & & 5 \\
\hline
\end{tabular}

a. Prespektif Keuangan yang diukur melalui indikator ROA. 
Gambar 1 Hasil penilaian ROA PT Sariguna Primatirta 2018-2020

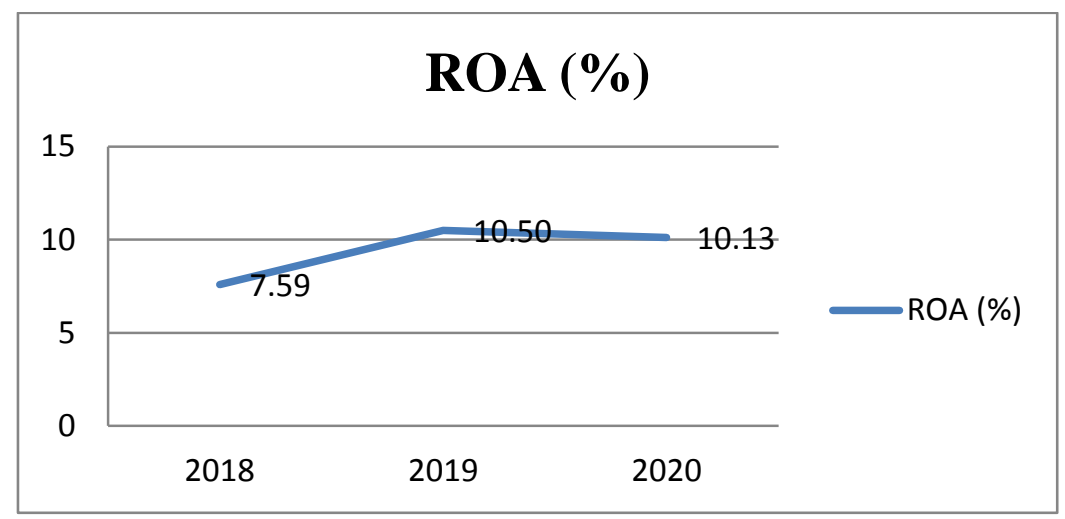

Sumber: Data diolah

Gambar 1 menunjukkan bahwa berdasarkan hasil analisa perhitungan statistik, ROA pada laporan keuangan PT Sariguna Primatirta pada tahun 2019 mengalami kenaikan dari 7,59\% ke 10,50\% dan pada tahun 2020 masih dalam kategori stabil walaupun terdapat penurunan dari $10,50 \%$ ke $10,13 \%$. Sedangkan, berdasarkan pada hasil perhitungan balanced scorecard menunjukkan bahwa pencapaian kinerja yang diukur menggunakan indikator ROA pada tahun 20192018 mengalami kenaikan kinerja mendapatkan score 2 dan pada tahun 2020-2019 mengalami penurunan kinerja mendapatkan score 1 (lihat Tabel 3).

b. Prespektif keuangan yang diukur melalui indikator ROE.

Gambar 2 Hasil penilaian ROE PT Sariguna Primatirta 2018-2020

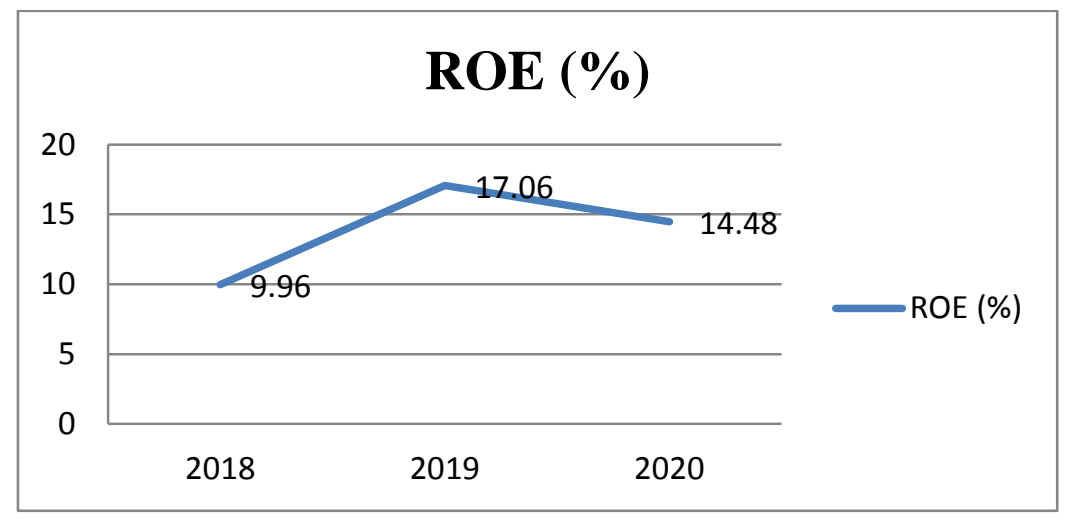

Sumber : Data diolah 
Gambar 2 menunjukkan bahwa menunjukkan bahwa berdasarkan hasil analisa perhitungan statistik, ROE pada laporan keuangan PT Sariguna Primatirta pada tahun 2019 mengalami kenaikan dari 9,96\% ke 17,06\% dan pada tahun 2020 mengalami penurunan dari $17,06 \%$ ke $14,48 \%$. Sedangkan, berdasarkan pada hasil perhitungan balanced scorecard menunjukkan bahwa pencapaian kinerja yang diukur menggunakan indikator ROE pada tahun 2019-2018 mengalami kenaikan kinerja mendapatkan score 3 dan pada tahun 2020-2019 mengalami penurunan kinerja mendapatkan score 1 (lihat Tabel 3).

c. Prespektif keuangan yang diukur melalui indikator OPM

Gambar 3 Hasil penilaian Operating Profit Margin PT Sariguna Primatirta 20182020

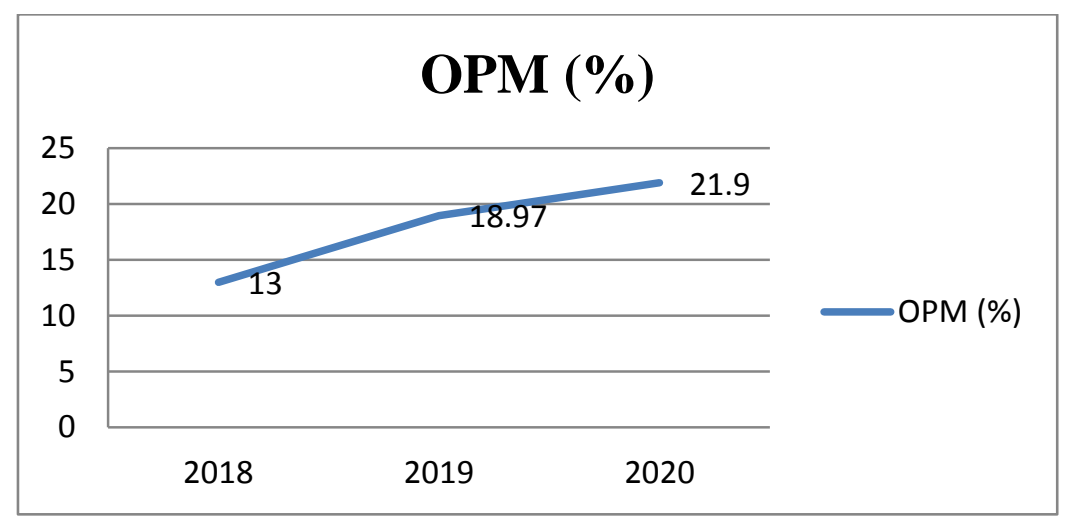

Sumber: Data diolah

Gambar 3 menunjukkan bahwa menunjukkan bahwa berdasarkan hasil analisa perhitungan statistik, OPM pada laporan keuangan PT Sariguna Primatirta pada tahun 2019 mengalami kenaikan dari 13\% ke 18,97\% dan pada tahun 2020 mengalami kenaikan dari $18,97 \%$ ke $21,9 \%$. Sedangkan, berdasarkan pada hasil perhitungan balanced scorecard menunjukkan bahwa pencapaian kinerja yang diukur menggunakan indikator OPM pada tahun 2019-2018 mengalami kenaikan kinerja mendapatkan score 1 dan pada tahun 2020-2019 mengalami penurunan kinerja namun masih mendapatkan score 1 (lihat Tabel 3). 
d. Prespektif keuangan yang diukur melalui indikator TATO

Gambar 4 Hasil penilaian Total Aset Turn Over PT Sariguna Primatirta 2018-2020

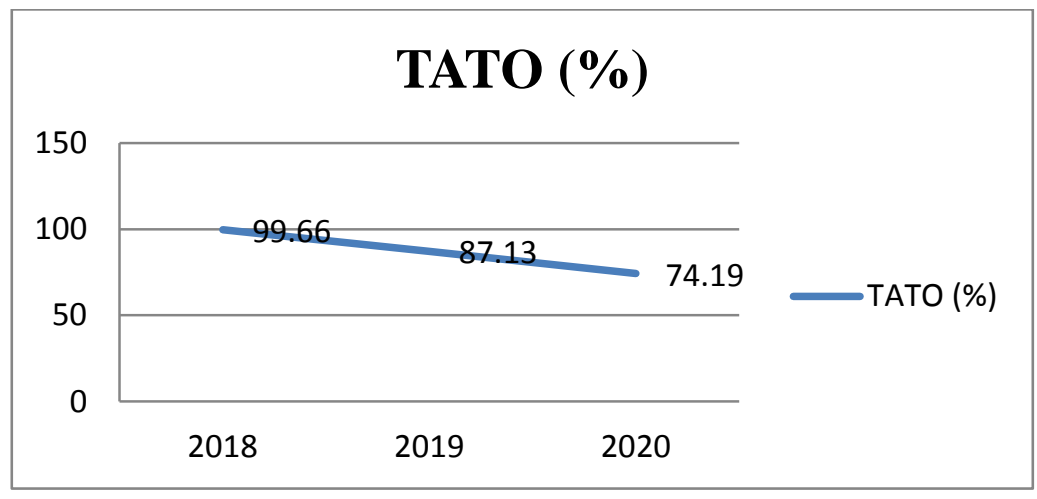

Sumber: Data diolah

Gambar 4 menunjukkan bahwa menunjukkan bahwa berdasarkan hasil analisa perhitungan statistik, TATO pada laporan keuangan PT Sariguna Primatirta pada tahun 2019 mengalami penurunan dari 99,66\% ke 87,13\% dan pada tahun 2020 mengalami penurunan dari $87,13 \%$ ke $74,19 \%$. Sedangkan, berdasarkan pada hasil perhitungan balanced scorecard menunjukkan bahwa pencapaian kinerja yang diukur menggunakan indikator ROE pada tahun 2019-2018 mengalami penurunan kinerja mendapatkan score 1 dan pada tahun 2020-2019 mengalami penurunan kinerja mendapatkan score 1 (lihat Tabel 3).

Secara umum hasil penilaian kinerja manajemen PT Sariguna Primatirta berdasarkan prespektif keuangan yang diukur melalui ROA, ROE, OPM dan TATO menunjukkan bahwa pada tahun 2019-2018 mendapatkan score 8 dan pada tahun 2020-2019 mendapatkan score 5 hal ini dapat diinterpretasikan bahwa selama tahun 2018 hingga 2019 kinerja manajemen PT Sariguna Primatirta dapat dikategorikan "Baik" terlihat dari pencapaian ROA, ROE, OPM yang meningkat walaupun TATO mengalami penurunan. Sedangkan, pada tahun 2019 hingga 2020 kinerja manajemen PT Sariguna Primatirta dapat dikategorikan "Cukup Baik" terlihat dari peningkatan OPM dan ROA yang masih dalam taraf stabil jika dibandingkan dengan tahun sebelumnya walaupun ROE dan TATO mengalami penurunan (lihat Tabel 3). 
2. Prespektif pelanggan diukur melalui indikator penerimaan kas dari pelanggan

Tabel 4 Hasil Penilaian Penerimaan Kas dari Pelanggan Prespektif Pelanggan PT Sariguna Primatirta 2018-2020 (dalam Jutaan)

\begin{tabular}{ccccc}
\hline Indikator & $\mathbf{2 0 1 8}$ & $\mathbf{2 0 1 9}$ & $\mathbf{2 0 2 0}$ & Average \\
\hline Penerimaan Kas dari Pelanggan & 816.023 & 1.060 .290 & 981.434 & 952.582 \\
\hline
\end{tabular}

Sumber : (PT Sariguna Primatirta Tbk, 2020)

Tabel 5 Hasil Penilaian Balanced Scorecard Prespektif Pelanggan

\begin{tabular}{ccccc}
\hline Indikator & $\mathbf{2 0 1 9 - 2 0 1 8}$ & $\begin{array}{c}\text { Score } \\
\mathbf{2 0 1 9 - 2 0 1 8}\end{array}$ & $\begin{array}{c}\text { Score } \\
\mathbf{2 0 2 0 - 2 0 1 9}\end{array}$ & $\begin{array}{c}\text { Score } \\
\mathbf{2 0 2 0 - 2 0 1 9}\end{array}$ \\
\hline $\begin{array}{c}\text { Penerimaan Kas dari } \\
\text { Pelanggan }\end{array}$ & $29,93 \%$ & $\mathrm{C}$ & $-7,44 \%$ & $\mathrm{D}$ \\
Total Score & & 2 & & 1 \\
\hline
\end{tabular}

Sumber : Data diolah

Tabel 5 menunjukkan bahwa hasil penilaian kinerja manajemen PT Sariguna Primatirta berdasarkan prespektif pelanggan yang diukur melalui indikator penerimaan kas dari pelanggan menunjukkan bahwa pada tahun 2019-2018 mendapatkan skor 2 dan pada tahun 2020-2019 mendapatkan skor 1. Hal ini dapat diinterpretasikan bahwa kinerja manajemen PT Sariguna Primatirta pada tahun 2018 hingga 2019 dapat dikategorikan "Baik" karena menunjukkan tingkat keberhasilan manajemen dalam meningkatkan kepuasan pelanggan terlihat dari meningkatnya pendapatan yang diterima dari pelanggan. Sedangkan, pada tahun 2019 hingga 2020 kinerja manajemen PT Sariguna Primatirta berdasarkan prespektif pelanggan dapat dikategorikan "Kurang Baik" terelihat dari penurunan penerimaan pendapatan dari pelanggan.

3. Prespektif Proses Bisnis Internal yang diukur melalui Operating Profit

Tabel 6 Hasil Penilaian Operating Profit Prespektif Proses Bisnis Internal PT Sariguna Primatirta 2018-2020 (dalam Jutaan)

\begin{tabular}{ccccc}
\hline Indikator & $\mathbf{2 0 1 8}$ & $\mathbf{2 0 1 9}$ & $\mathbf{2 0 2 0}$ & Average \\
\hline Operating Profit & 108.042 & 205.769 & 213.024 & 175.612 \\
\hline
\end{tabular}

Sumber : Laporan Keuangan PT Sariguna Primatrta 2018-2020

Tabel 7 Hasil Penilaian Balanced Scorecard Prespektif Proses Bisnis Internal

\begin{tabular}{ccccc}
\hline Indikator & $\mathbf{2 0 1 9 - 2 0 1 8}$ & $\begin{array}{c}\text { Score } \\
\mathbf{2 0 1 9 - 2 0 1 8}\end{array}$ & $\begin{array}{c}\text { Score } \\
\mathbf{2 0 2 0 - 2 0 1 9}\end{array}$ & $\begin{array}{c}\text { Score } \\
\mathbf{2 0 2 0 - 2 0 1 9}\end{array}$ \\
\hline $\begin{array}{c}\text { Operating Profit } \\
\text { Total Score }\end{array}$ & $90,45 \%$ & $\mathrm{~B}$ & $3,52 \%$ & $\mathrm{C}$ \\
\hline
\end{tabular}

Sumber: Data diolah 
Tabel 7 menunjukkan bahwa hasil penilaian kinerja manajemen PT Sariguna Primatrita berdasarkan prespektif pelanggan yang diukur melalui indikator operating profit menunjukkan bahwa pada tahun 2019-2018 mendapatkan skor 3 dan pada tahun 2020-2019 mendapatkan skor 2. Hal ini dapat diinterpretasikan bahwa kinerja manajemen PT Sariguna Primatrita pada tahun 2018 hingga 2019 dapat dikategorikan "Sangat Baik" terlihat dari peningkatan operating profit yang signifikan menunjukkan keberhasilan manajemen dalam menjalankan proses bisnisnya guna meningkatkan keuntungan. Sedangkan pada tahun 2019 hingga 2020 dapat dikategorikan "Baik" terlihat dari peningkatan operating profit walaupun tidak begitu signifikan namun sudah menunjukkan keberhasilan manajemen dalam menjalankan proses bisnisnya.

4. Prespektif Pembelajaran dan Pertumbuhan

Tabel 8 Hasil Penilaian Tingkat Produktivitas Karyawan PT Sariguna Primatirta 2018-2020

\begin{tabular}{ccccc}
\hline Indikator & $\mathbf{2 0 1 8}$ & $\mathbf{2 0 1 9}$ & $\mathbf{2 0 2 0}$ & Average \\
\hline $\begin{array}{c}\text { Net Income (dalam } \\
\text { Jutaan) }\end{array}$ & 63.262 & 130.756 & 132.772 & 175.612 \\
$\begin{array}{c}\text { Total Karyawan } \\
\text { Net Income / Total } \\
\text { Karyawan }\end{array}$ & 734 & 928 & 869 & 844 \\
\hline
\end{tabular}

Sumber: Data diolah

Tabel 9 Hasil Penilaian Balanced Scorecard Prespektif Pertumbuhan dan Pengembangan

\begin{tabular}{ccccc}
\hline Indikator & $\mathbf{2 0 1 9 - 2 0 1 8}$ & $\begin{array}{c}\text { Score } \\
\mathbf{2 0 1 9 - 2 0 1 8}\end{array}$ & $\begin{array}{c}\text { Score } \\
\mathbf{2 0 2 0 - 2 0 1 9}\end{array}$ & $\begin{array}{c}\text { Score } \\
\mathbf{2 0 2 0 - 2 0 1 9}\end{array}$ \\
\hline $\begin{array}{c}\text { Net Income / Total } \\
\text { Karyawan }\end{array}$ & $63,48 \%$ & $\mathrm{~B}$ & $8,43 \%$ & $\mathrm{C}$ \\
Total Score & & 3 & & 2 \\
\hline
\end{tabular}

Sumber: Data diolah

Tabel 9 menunjukkan bahwa hasil penilaian kinerja manajemen PT Sariguna Primatrita berdasarkan prespektif pertembuhan dan pengembangan yang diukur melalui indikator tingkat produktivitas karyawan menggunakan Net Income dibagi dengan keseluruhan karyawan menunjukkan bahwa pada tahun 2019-2018 mendapatkan skor 3 dan pada tahun 2020-2019 mendapatkan skor 2. Hal ini dapat diinterpretasikan bahwa kinerja manajemen PT Sariguna Primatrita pada tahun 2018 hingga 2019 dapat dikategorikan "Sangat Baik" terlihat dari peningkatan produkvitias karyawan dalam menghasilkan pendapatan perusahaan. Sedangkan pada tahun 2019 hingga 2020 dapat dikategorikan "Baik" terlihat dari peningkatan 
produktivitas setiap karyawan dalam menghasilkan pendapatan untuk perusahan walaupun tidak begitu signifikan namun sudah menunjukkan keberhasilan manajemen dalam menjalankan bisnisnya.

\section{KESIMPULAN}

Berdasarkan hasil penelitian dari analisis kinerja manajemen PT Sariguna Primatirta TBK menggunakan metode balanced scorecard periode 2018 hingga 2020 yang diukur melalui 4 prespektif diantaranya prespektif keuangan, pelanggan, proses bisnis internal serta pertumbuhan dan pengembangan menunjukkan bahwa kinerja perusahaan pada tahun 2018 hingga 2019 mendapatkan total skor 16 dan pada tahun 2019 hingga 2020 mendapatkan total skor 20. Kondisi tersebut menunjukkan bahwa kinerja perusahaan dalam keadaan "Baik" pada tahun 2018 hingga 2019 terlihat dari pencapaian manajemen yang cukup optimal mengelola perusahaan dalam mencapai tujuannya yakni meningkatkan laba perusahaan. Namun, pada tahun 2019 hingga 2020 kinerja perusahaan mengalami penurunan, hal ini mengindikasikan bahwa terjadi ketidakoptimalan dalam menjalankan operasional perusahaan terbukti dari penurunan total aktiva turn over yang menunjukkan bahwa perusahaan kurang efektif dan efisien dalam memanfaatkan seluruh aset yang ada dalam mencapai tujuan perusahan.

Saran dari penulis kepada PT Sariguna Primatirta TBK agar meningkatkan kinerja manajemen dengan melakukan evaluasi terhadap implementasi strategi yang telah dijalankan dan meningkatkan pelayanan kepada konsumen agar kedepannya perusahaan dapat memperoleh prestasi yang lebih baik mengingat besarnya potensi pasar dan produk yang dihasilkan sehingga pandemi menjadi momentum yang tepat untuk mengambil langkah agar bisa menguasai pangsa pasar. Saran untuk penelitian selanjutnya diharapkan agar menggunakan komparasi metode lain guna memperkaya cakupan penelitian.

\section{DAFTAR PUSTAKA}

Aini, P. Q., \& Sutjahyani, D. (2020). Analisis Metode Balanced Scorecard Terhadap Pengukuran Kinerja Perusahaan PT. Golden Teknik Sidoarjo Tahun 2013-2015. JEA17: Jurnal Ekonomi Akuntansi, 5(1), 53-62. https://doi.org/10.30996/jea17.v5i1.4116

Aramana, D. (2020). Penerapan Kinerja Dengan Pendekatan Balanced Scorecard Pada PT Pos Indonesia Cabang Kutacane. Jurnal Akuntansi Dan Keuangan, 8(2), 91-96. https://doi.org/10.29103/jak.v8i2.2616

Badan Pusat Statistik. (2021). Hasil Sensus Penduduk 2020. Diambil 23 Juni 2021, 
https://www.bps.go.id/pressrelease/2021/01/21/1854/hasil-sensuspenduduk-2020.html

Briawan, D., Sedayu, T. R., \& Ekayanti, I. (2011). Kebiasaan Minum dan Asupan Cairan Remaja Di Perkotaan. Jurnal Gizi Klinik Indonesia, 8(1), 36-41. https://doi.org/10.22146/ijen.17729

Creswell, J. W. (2017). RESEARCH DESIGN, Pendekatan Metode Kualitatif, Kuantitatif dan Campuran. Yogyakarta: Pustaka Pelajar.

Ernovitania, Y., \& Sumarmi, S. (2017). Hubungan Antara Pengeluaran Untuk Minum Dan Pola Konsumsi Air Dengan Status Hidrasi Pada Siswi Smp Unggulan Bina Insani Surabaya. The Indonesian Journal of Public Health, 12(2), 276-285. https://doi.org/10.20473/ijph.v12i2.2017.276-285

Fahrudin, W. A. (2020). Analisis Pengukuran Kinerja Menggunakan Balance Scorecard Untuk Menentukan Key Performance Indicator di PT Mulia Artha Anugerah. JITMI (Jurnal Ilmiah Teknik dan Manajemen Industri), 3(1), 15-23. https://doi.org/10.32493/jitmi.v3i1.y2020.p15-23

Farhan, A., Kurniawan, D., \& Fitria, L. (2016). Penyusunan Rencana Strategis Di PT. Panairsan Pratama Menggunakan Metode Balanced Scorecard. REKA INTEGRA, 4(1), 205-216.

Ikasari, D. M., Silalahi, P. D., \& Effendi, U. (2018). Pengukuran Kinerja Perusahaan Dengan Menggunakan Metode Balanced Scorecard (Studi Kasus di PG Kremboong, Sidoarjo, Jawa Timur). PROCEEDINGS OF NATIONAL COLLOQUIUM RESEARCH AND COMMUNITY SERVICE, 2, 6-12. https://doi.org/10.33019/snppm.v2i0.581

Jayusman, I., \& Shavab, O. A. K. (2020). Aktivitas Belajar Mahasiswa Dengan Menggunakan Media Pembelajaran Learning Management System (IMS) Berbasis Edmodo Dalam Pembelajaran Sejarah. Jurnal Artefak, 7(1), 13-20. https://doi.org/10.25157/ja.v7i1.3180

Jumingan, J. (2017). Analisis Kinerja Manajemen Berdasarkan Balanced Scorecard. Jurnal Bisnis Dan Manajemen (Journal of Business and Management), $15(1)$ 45-56. 
https://doi.org/10.20961/jbm.v15i1.4114

Kasmir. (2019). Analisis Laporan Keuangan. Depok: Rajawali Press.

PT Sariguna Primatirta Tbk. (2020). Laporan Tahunan. Diambil 23 Juni 2021, dari https://tanobel.com/laporan-tahunan/

Putra, B. I. (2012). Analisis Pengukuran Kinerja dengan Metode Balance Score Card (BSC) Di CV MCH Sidoarjo. Tekmapro: Journal of Industrial Engineering and Management, 1(2), 1-15.

Rahmawati, W. S., Dzulkirom AR, M., \& Husaini, A. (2013). Analisis Penerapan Metode Balanced Scorecard Untuk Mengukur Kinerja Perusahaan (Studi Pada PT. PLN (persero) Area Pasuruan Periode 2010-2011). Jurnal Administrasi Bisnis, 2(1), 172-181.

Riana, D. (2017). Pengukuran Kinerja Perusahaan PT Indofood Dengan Menggunakan Balanced Scorecard. Jurnal SEKURITAS (Saham, Ekonomi, Keuangan Dan Investasi), 1(2), 42-53. https://doi.org/10.32493/skt.v1i2.746

Top Brand Index. (2021). Diambil 23 Juni 2021, dari https://www.topbrandaward.com/en/top-brand-index-int/

Wutun, M. M. (2020). Analisis Balanced Scorecard Dalam Pengukuran Kinerja Radio Republik Indonesia Kupang. Inspirasi Ekonomi: Jurnal Ekonomi Manajemen, 2(4), 1-14. https://doi.org/10.32938/jie.v2i4.865 